A relationship exists between certain protracted viral, bacterial and parasitic infections on one hand and development of tumours on the other.

A relationship was proven between persistent infection with highly oncogenic types of human papilloma virus (HPV) and the development of precancerous lesions and uterine cervical cancer, a significant proportion of cancers of the anus, penis, vulva and vagina, and a lower proportion of cancers of the oral cavity and the larynx (infection with lowoncogenic types of the virus).

It is estimated that around $54 \%$ of primary hepatic carcinomas worldwide (hepatocellular carcinoma - HCC) are directly linked to persistent infection with hepatitis type B virus (HBV) and $31 \%$ of the cancers result from persistent infection with hepatitis type $\mathrm{C}$ virus (HCV). Human immunodeficiency virus (HIV) induces increased morbidity due to certain malignant tumours. The index diseases for the acquired immune deficiency syndrome include Kaposi sarcoma, non-granulomatous lymphomas, primary cerebral lymphoma and carcinoma of the uterine cervix. Epstein-Barr virus (EBV), also known as human herpes virus (4-HH-4), induces Burkitt's lymphoma, but its DNA was also detected also in malignant granulomatosis and in tumours of nasopharynx. Human T-lymphotropic virus (HTLV), particularly in certain regions of the globe, is linked to development of the T cell leukaemia. Among bacteria, relationships with cancer development are manifested by Helicobacter pylori and Chlamydia trachomatis. The first has been classified as a group I carcinogen: chronic infection, with type A of $H$. pylori in particular, leading to gastric cancer and gastric lymphoma, Chlamydia trachomatis, and its serotypes $\mathrm{G}, \mathrm{I}$ and D are thought to represent strong co-factors in development of cancer of the uterine cervix. The parasites with proven carcinogenic effects include Schistosoma haematobium, Opisthorchis viverrini and Clonorchis sinensis. The common mechanism involves chronic inflammation which in the case of Schistosoma haematobium results in development of urothelial bladder cancers, particularly in certain endemic regions of the world. The remaining two parasites, particularly in eastern Asia endemically lead to cancers of the biliary ducts.

Key words: cancer, inflammation, HPV, HBV, HCV, HIV, EBV, HIV, HTLV, Helicobacter pylori, Chlamydia trachomatis, Schistosoma haematobium, Opisthorchis viverrini, Clonorchis sinensis.

\section{The influence of viral, bacterial and parasitic infections on the development of neoplasia}

\author{
Anna Markowska ${ }^{1}$, Jolanta Lubin², Karolina Jaszczyńska-Nowinka ${ }^{2}$, \\ Monika Pawałowska², Radosław Mądry
}

1Department of Perinatology and Gynaecology, University of Medical Sciences, Poznań 2Department of Oncology, University of Medical Sciences, Poznań

Since the $19^{\text {th }}$ century, when the German pathologist and anthropologist Rudolf Virchow hypothesized that chronic inflammation may lead to the onset of carcinogenesis, this intriguing connection has been proved many times.

Two epidemiologists, Higgison and Muir [1], recognize environment and lifestyle, including inflammatory processes, as important factors responsible for $80 \%$ of cancer cases. Recent research indicates the crucial role of proinflammatory cytokines and chemokines produced by inflammation-induced lymphoid cells which in turn activate the nuclear factor $\kappa B$ (NF-KB), along with the signal transporters and transcription activators (STAT - 1, STAT - 3). They regulate a number of mechanisms responsible for the development of cancer, including cell proliferation and antiapoptotic activity lower the immunologic response and facilitate cancer invasion [2, 3]. The relation between persistent viral, bacterial and parasitic infections is relatively well identified. We would like to present a review of chronic infections that lead to malignant cancers.

\section{Viruses}

Human papillomavirus

Human papillomavirus (HPV) belongs to the Papillomaviridae family and is a small virus formed by 72 pentameric capsomeres, $55 \mathrm{~nm}$ in diameter. The genetic material in the form of spherical, double-stranded DNA is composed of 8000 bases. The HPV genome is composed of three regions: early genes (E1, E2, E4, E5, E6, E7) that encode proteins responsible for transcription, replication and interaction with the host's genome, late genes (L1 and L2) encoding mainly capsid proteins responsible for the differentiation of HPV types, and a non-coding long control region (LCR) between the two.

From over 100 different types of HPV identified, 12 (16, 18, 31, 33, 35, 39, $45,51,52,56,58,59)$ belong to the high-risk group and were classified as class I carcinogens by IARC (International Agency for Research Cancer) [4]. HPV 68, 69, 73 and 78 were also assigned to this group [5]. The most common HPV in cases of cervical cancer are 16, 18, 45 and 31 - traces of their DNA were detected in $99.7 \%$ of cases of this type of cancer. The histological type of cancer (squamous, glandular) and geographic region determine the prevalence of different types of HPV DNA [6].

After the host cell is infected, the virus undergoes replication and produces multiple copies. There is overexpression of the highly oncogenic viral E6 and E7 oncoproteins which are capable of binding with cell cycle suppressor proteins, i.e. p53 and Rb. The newly formed complexes are then inactivated in the course of a ubiquitination in proteasomes. As a result of this mechanism the suppressing anti-oncogenic activity of p53 and Rb is halted and the E6 and E7 oncoproteins can immortalize cells. All that in the absence of apoptosis leads to the development of neoplastic phenotype [5]. 
High-risk HPVs have been found to be associated with cervical, anal, vulva, vaginal, penile and oropharyngeal and laryngeal cancer $[6,7]$.

Cervical cancer is a global problem; it is the second most common cancer in the world. Worldwide registers estimated that in 2002 there were 493000 cases of cervical cancer and 274000 deaths due to that disease. Women from developing countries are affected more often than those from the developed counties. The highest standardized morbidity ratio occurs in sub-Saharan Africa, Melanesia, Latin America, and in the Caribbean Islands and amounts to 42.7-26.2 per 100 000. The lowest are in Japan, North America, Australia and New Zealand -8.0-5.8. Mortality among women with cervical cancer reaches 55\% [8]. In Poland, cervical cancer is responsible for $5.2 \%$ of all cancer cases, the standardized morbidity ratio is 11.3 and mortality -5.64 per 100000 [9].

HPV infection is common among sexually active women and is transmitted during sexual intercourse; $80 \%$ of women are affected by it. Incidences of mother-to-child transmission have also been described [5].

In $70 \%$ of women infections clear spontaneously in a year and in $90 \%$ in two years (the average being eight months). However, these women do not develop immunity against HPV reinfection. Of all infected, 10\% develop persistent infection which may progress to precancerous lesions (cervical intraepithelial neoplasia - CIN) and invasive cervical cancer. Persistent infection has been found to be a necessary factor. This factor along with smoking, long-term hormonal contraception, large number of partners, HPV infection, HIV infection, HSV2 (herpes simplex 2) infection and chlamydia infection may increase the risk of progression to $\mathrm{CIN}$ and invasive cancer. Progression to CIN and invasive cancer is a long-term process.

The virologist Harald zur Hausen was awarded a Nobel Prize in 2008 for describing the role of HPV in the carcinogenesis of human cancers.

Different HPVs also cause other types of cancers; HPV DNA has been detected in the following types of cancers $(4,6,8)$ : - anal cancer - HPV 16, 18, 31 and 33 identified in 90\% of cases. More common in women. Men who have other female partners or homosexual men increase the risk of this type of cancer,

- penile cancer - HPVs account for $40 \%$ of all cases,

- vulva and vaginal cancer $-40 \%$ of cancer cases, mainly HPV DNA 16,

- oropharyngeal and laryngeal cancers - less than 12\% of cases (mainly HPV strains 6 and 11).

Two vaccines against HPV have been approved in more than 100 countries [11]. They both contain virus-like particles (VLP) assembled from recombinant L1 capsid proteins of different types of HPV.

Cervarix, a bivalent vaccine against HPV types 16 and 18 contains an adjuvant ASO4 designed to boost the immune system response; it has also been shown to be effective with HPV 31, 33 and 45 together constituting, the five main HPV types responsible for cervical cancer, including adenocarcinoma.
Silgrad, a quadrivalent vaccine, has proved to be effective in preventing the highly oncogenic HPV types 16, 18 and 31 , also providing protection against genital warts and respiratory papillomatosis caused by HPVs 6 and 11. Cervarix efficacy is proven for 6.4 years while Silgrad efficacy is proven for 5 years. The vaccines are recommended mostly to those who have not been infected with HPV at the moment of vaccination (NAIVE). The vaccines are almost $100 \%$ effective in preventing cervical cancer, $40 \%$ effective in vulva cancer prevention, $60 \%$ in vaginal cancer and $80 \%$ in anal cancer $[5,11]$.

Treatment of the abovementioned cancers covers too broad a scope, therefore it will not be discussed in this paper.

\section{Hepatitis B virus}

Hepatitis B virus (HBV) is a small enveloped DNA virus, hepatotropic and lymphotropic, a member of the Hepadnaviridae family of viruses. This virus causes hepatitis B. Possible routes of transmission include: non-oral, sexual contact and vertical transmission from mother to child. There are over $350 \mathrm{~m}$ chronic carriers in the world. Morbidity is particularly high in Eastern Europe and Southeast Asia, China, Russia, Africa, South and Latin America and in the Pacific Islands. In Poland the morbidity in the late 1970 s and to mid-1980s was $43 / 100000$ and dropped to 4.4/100 000 in 2003 due to a nationwide vaccination programme and improvement in sterilization of medical equipment and materials [12].

The acute form causes liver inflammation, vomiting, jaundice and rarely death. Chronic hepatitis B may eventually lead to liver cirrhosis and liver cancer.

Hepatocellular carcinoma (HCC) is the sixth most common malignant type of cancer and the third most deadly cancer. The incidence is three times higher among men than women (standardized ratio - 14.9 vs. 5.5). The prevalence of this virus differs according to the geographical region, e.g. in China the standardized morbidity ratio is 37.9 vs. 14.2, whereas in eastern Europe it is 5.3 vs. 2.4. The mortality rate is close to the morbidity rate [8].

It is estimated that around $54 \%$ of HCC cases are secondary to HBV infection [7]. In over $90 \%$ of HBV-antigen positive patients, integration of HBV-DNA into the host genome has been reported [13]. Integration of both genetic materials is conducted using two repeat sequences, DR1 and DR2, located within the 5'end of the HBV genome, in the gene $X$. During genome integration inversion, duplication, deletion and chromosomal translocation may occur [14].

The role of tumour-suppressor protein p53 is another important problem in carcinogenesis, as it prevents uncontrollable cell growth. The inactivation of p53 leads to replication of cells with damaged DNA, which undergo apoptosis or transformation [15]. In HCC associated with chronic hepatitis $B$ the integration of protein $X$ with p53 takes place and eventually leads to inactivation of p53. This in turn causes uncontrolled replications and transcriptions of the damaged cellular DNA at the helicase level that may promote new mutations and neoplastic changes. During chronic infection, as the amount of $\mathrm{HBx}$ increases and it gradually accumulates in the infected cell, p53 transcription is stopped inducing phenotypic lesions in affected cells. 


\section{Hepatitis C virus}

Hepatitis C virus (HCV) is a small enveloped, single stranded RNA virus of the family Flaviviridae and Hepacivirus genus. It is estimated that $750 \mathrm{~m}$ people are infected with this virus worldwide and around 700000 in Poland. There are 2000 new cases of hepatitis a year in Poland (5.9/ 100000 incidents in 2003), mainly among adults, with 60-90\% infections of in-hospital and out-patient origin [6].

Hepatitis C virus is the cause of Hepatitis C. As in the case of Hepatitis $B$, it has been recognized as a cause of liver cancer and liver cirrhosis. It is reported, that $31 \%$ of primary liver cancers are secondary to Hepatitis C infection [7].

Hepatitis C virus is an oncogenic virus. However the pathogenesis of hepatocellular carcinoma in patients with chronic HCV has not yet been found. Unlike hepatitis B virus, HCV RNA does not integrate with the host genome and so the neoplastic transformation must progress differently. Studies confirm that the neoplastic process develops through the stage of cirrhosis correlated with chronic hepatitis C. Increased production of mature virions together with prolonged hepatocyte damage progress to liver cancer. This is probably connected with chronic liver inflammation, necrosis and hepatocyte repair. The core region triggers hepatocyte apoptosis and that in turn leads to compensatory hyperplasia supplementing liver parenchyma losses and facilitates neoplastic changes.

The key element of carcinogenesis in patients with cirrhosis is the hepatocyte transformation into cancer cells. It may be due to improper hormone regulation, alterations of cell spatial arrangement (remodeling), increased growth factor synthesis and abnormal oncogene expansion. Prolonged exposure to these factors as well as other oncogenic factors of exogenous origin may cause liver cancer [17].

The virus often escapes control of the host immune system by mutating and then infecting the immune cells. The presence of HCV has been found not only in liver cells, but also in the circulating lymphocytes, lymph nodes, salivary glands and kidneys. This may lead to secondary diseases of autoimmune and eventually lymphoproliferative character. HCV increases the risk of lymphoproliferative disorders probably as a result of chronic stimulation of HCV-specific B cell lymphocyte receptors with accompanying CD8+ Tc lymphocyte anergy [18]. The pathogenesis of non-Hodgkin lymphoma in the course of HCV infection must therefore be different than the role of the virus in the development of liver cancer. HCV is not directly an oncogenic virus for normal lymphoid cells. Due to HCV persistent stimulation of the immune system, new lymphocyte subpopulations emerge producing different classes of immunoglobulins, including cryoglobulins - proteins that precipitate at low temperatures and dissolve again at higher temperatures. There is a linear relation between the cryoglobulin concentration and HCV RNA concentration. Cryoglobulinaemia is classically grouped into three types. HCV infection is typically associated with type II (mixed, MC: monoclonal IgM and polyclonal IgG) and type III (polyclonal IgG and IgM). There is a clinically significant and strongly documented link between HCV infection and mixed cryoglobulinaemia. In this medical condition immune complexes, some contain- ing a rheumatoid factor (RF), can be detected in blood. Typical symptoms are connected with vasculitis and include: Raynaud's phenomenon, vascular purpura, joint pains, peripheral polyneuropathy and renal failure.

\section{Human immunodeficiency virus}

Human immunodeficiency virus (HIV) is a single-strand RNA retrovirus of the family Retroviridae and Lentivirus genus.

The single-stranded RNA is tightly bound to protein p7, enzymes needed for replication (reverse transcriptase, proteases, ribonuclease and integrase) and other nucleocapsid proteins. The nucleocapsid is surrounded by protein p17 and this, in turn, is enclosed in two phospholipid envelopes taken from the membrane of the host cell. On the surface of the envelope there is a glycoprotein gp 120 that enables the virus to attach to and fuse with host cells and infect them. Cells susceptible to HIV infection include CD4 ${ }^{+} T$ cells, monocytes/macrophages, dendritic cells, epithelial cells, white blood cells, astroglial and oligodendroglial cells, bone marrow and thymic precursor cells. There are two species of HIV:

- HIV-1, the most common, globally prevalent,

- HIV-2, confined to West Africa, sporadic cases in Europe and the USA.

Human immunodeficiency virus is the major viral pathogen transmitted by blood-borne, sexual and vertical routes.

It is estimated that over $39 \mathrm{~m} / \mathrm{n}$ people were infected with HIV in 2004, 5 m of new cases and 3 m AIDS-related (Acquired Immune Deficiency Syndrome - due to chronic HIV infection) deaths are reported each year.

The majority of infections in Poland occur among drug addicts, but the data from recent years show an increase in heterosexually transmitted HIV infections (since 2002 there are reports of more people infected through heterosexual relations than intravenous drug injection). The morbidity rate in Poland is estimated to be around 0.3-3.5/100 000/per year, depending on the region [19].

Loss of cell-mediated immunity is linked to increased cancer incidence. According to the prevailing classification of HIV/AIDS infection based on clinical presentation and laboratory criteria, namely the level of CD4 phenotype cells, the following are considered to be AIDS index diseases: Kaposi's sarcoma, non-Hodgkin lymphoma, PCNSL (primary cerebral lymphoma) and cervical cancer [20].

Kaposi's sarcoma (KS) is a malignant neoplasm originating from mesenchyme, of angiosarcoma type. This opportunistic cancer is caused by a sexually acquired infection with human herpesvirus 8 (HHV8), discovered in 1995.

In the course of progressive impairment of cellular immunity HIV-positive patients develop some nodular lesions typical for sarcoma (25\%) on the surface of mucosa, skin and, less frequently, lymph nodes, gastrointestinal tract and lungs with characteristic intensely red cutaneous changes (40\%) or, less often, infiltrating (15\%) or lymphadenopathic (20\%) lesions.

Although the causal factor for KS and HIV-associated KS has been discovered, KS pathogenesis remains controver- 
sial and is still subject to research. KS progresses in a complex and multistage fashion. Due to its capacity for transformation, HHV-8 changes the phenotype along with the function of the infected mesenchymal precursor cells. Some alterations in the cellular genome appear followed by disorders in repair processes and intercellular communication. This leads to abnormalities in proliferation regulatory processes and excessive proliferation of altered cells, not amenable to apoptosis, which, in turn, favours expansion of AIDS-KS. The fact that AIDS-KS develops only in some patients infected with HHV-8 shows a significant role of cofactors in this process. The contributing factors are: coinfections with HSV, EBV, CMV, HHV-6, HIV itself, some concomitant bacterial and fungal infections as well as some hormones (androgens and glucocorticoids) [19-21].

Non-Hodgkin lymphoma (NHL) incidence rates are 100 times higher in cases of the HIV infection in comparison to the general population. In 2002, an estimated 310000 people were diagnosed with NHL worldwide accounting for $2.8 \%$ of all cancers. AIDS-related NHL is present in about $3 \%$ of HIV carriers. The most common types are:

- systemic and generalized malignant lymphoma,

- primary central nervous system lymphoma.

Systemic lymphomas are either moderately or highly aggressive with rapid extranodal involvement. Primary central nervous system lymphoma occurs in severe immunosuppression, is located itself mostly in the grey matter and does not undergo dissemination [19].

There is no single aetiological factor for NHLs. The basic factor is chronic stimulation with various viral antigens followed by B-cell clone proliferation, oncogene stimulation, deregulation and proliferation of some cytokines (increase in production of interleukins 1, 6 and 10 as well as growth factors indicating the B-cells' proliferation-stimulating properties) and neoplastic transformation in each cell line.

There is no evidence that HIV has any direct influence on these processes [21].

Other non-AIDS-defining cancers, but frequently coinciding with this syndrome are: Hodgkin's Disease (HD), squamous cell carcinoma (SCC), malignant melanoma, plasmocytoma, colon adenocarcinoma, testicular cancer, and basal cell carcinoma (BCC) [20].

\section{Epstein-Barr virus}

Epstein-Barr virus (EBV), also called human herpes virus 4 (HHV-4), is part of the Herpesviridae family of DNA viruses. It was discovered by Michael Epstein and Yvonne Barr in 1964 during their research on Burkitt's lymphoma [22]. This large virus is one of the most commonly occurring worldwide, with most infections asymptomatic. However, some symptomatic patients manifest infectious mononucleosis, non-Hodgkin lymphoma, including Burkitt's lymphoma, Hodgkin's disease (HD), or nasopharyngeal carcinoma; in recent years it has also been suggested that it may be the cause of the chronic fatigue syndrome and depression, also known as Chronic Epstein-Barr Virus (CEBV) and hepatitis. EBV infections are most prevalent in developing countries, in populations of low socioeconomic status, although it has been shown that among the US popu- lation around $85 \%$ of adults aged $35-40$ are infected with viruses of the herpes family [23].

The Global Cancer Statistics epidemiological report estimated that in 2002, 301000 cases of non-Hodgkin lymphoma were diagnosed, accounting for $2.8 \%$ of all cancers in the world. NHLs are slightly more common in the following developed countries: Australia, the United States, Central Europe, the Pacific Islands; they are less common in Asia and Eastern Europe. A higher morbidity rate of the endemic variant of Burkitt's lymphoma can be observed among children in tropical Central Africa [24].

There are two EBV types, type A and B; they can simultaneously infect the same person, type $B$ is more common in Africa and among people with immunodeficiency. The virus is usually transmitted in the saliva.

EBV-infected B lymphocytes carry the viral genome in a latent form. In immunosuppressed carriers, including patients with acquired immune deficiency syndrome (AIDS), patients under immunosuppressive treatment and after organ transplantation, viral activation or reactivation occurs more often leading to symptomatic EBV infection [25].

The short fragments of viral RNA called EBERs (Epstein-Barr virus-encoded small RNAs) play a crucial role in the process of transformation of the infected B-lymphocytes; moreover, they also prevent IFN- $\alpha$-mediated apoptosis of those cells by inhibiting phosphorylation of RNA-activated protein kinase (PKR). Furthermore, EBERs induce the expression of interleukin-10 (IL-10) in the Burkitt's lymphoma cells, insulin-growth factor (IGF-1) in the nasopharyngeal carcinoma cells, interleukin-9 (IL-9) in T-lymphocytes and interleukin-6 (IL-6) in lymphoblasts. All mentioned cytokines act as autocrine growth factors leading to the neoplastic transformation [25].

Activation of one of the three EBV membrane antigens, namely LMP1 (latent membrane protein) can also induce proliferation of B-cells. Binding of this protein to the tumour necrosis factor receptors TRAF-1 and TRAF-2 (tumour necrosis factor receptor-associated factor 1,2 ) causes the activation of antiapoptotic transcription factors: NF-кB (nuclear factor $\kappa \mathrm{B}$ ) and AP-1 (activating protein 1) [26].

\section{Human T-lymphotropic virus}

Human T-lymphotropic virus (HTLV), also called human T-cell leukaemia/lymphotropic virus, is a single-stranded RNA retrovirus. The endemic incidence of Adult T cell leukemia (ATL) in specific regions of Japan triggered the search for the aetiological agent of this disease in the 1970 s. In 1981, HTLV-1 was diagnosed in a patient with cutaneous T-cell lymphoma [27]. An estimated 20 to $30 \mathrm{mln}$ people are infected with HTLV worldwide and its endemic incidence is reported mainly in Japan (10-20\% of the overall infected population), Central Africa, the Caribbean Islands, southeastern states of the US, and south-eastern parts of South America along with Taiwan, Papua New Guinea and Trinidad helped to compile a "map" of ATL regions. The virus is most commonly transmitted in the blood, breast milk, and semen (mainly male-to-female transmission) [28].

The virus infects not only $T$ cells, but also B cells, fibroblasts and endothelial cells, however, under in vitro conditions only CD4 T-cells can be immortalized [29]. 
The proteins Tax and Rex play a crucial role in the progression of HTLV-1-associated ATL. Once the virus enters the host cell, it enters the latent phase, giving only asymptomatic, yet seropositive infection. Around 5\% of HTLV-1positive carriers develop disease-related conditions within 10-40 years after the infection, including: the abovementioned Adult T cell leukaemia, neurological disorders (polyneuropathy, tropical spastic paraparesis, polymyositis, meningitis), and choroiditis [30]. Tax protein capable of binding with transcription factors NF $\kappa b$, CBP protein and HDAC, leads to a number of changes in transcription of regulatory genes associated with cellular proliferation and apoptotic processes. This results in stimulation of synthesis of interleukin 2 (IL-2) and its receptor (IL-2R), granulocytemacrophage colony-stimulating factor (GM-CSF), molecules of major histocompatibility complex, class I (MHC Class-I), proto-oncogenes c-fos and c-egr, etc. Rex is a regulatory protein responsible for expression of incompletely spliced transcripts of viral RNA encoding retroviral structural proteins and enzymes [33].

\section{Bacteria}

Helicobacter pylori (HP) is a helix-shaped, Gram-negative bacterium, 0.5-3 $\mu \mathrm{m}$ in size, equipped with flagella. It colonizes the mucous membrane of the stomach and duodendum - by producing the urease enzyme it is capable of neutralizing the acidic environment, making it more likely to favour its survival.

Helicobacter pylori is present in different age groups, including in children, with prevalence rates varying according to nation and geographical regions. In developing countries with low hygiene standards (India, Bangladesh) HP is present in $90 \%$ of adults $[35,36]$. The infection occurs mainly by food-borne transmission and close interpersonal contact. More than $80 \%$ of the infections are asymptomatic.

The International Agency for Research on Cancer (IARC) classifies HP as a Group I carcinogen [4].

Chronic HP infection is mainly associated with the influence of gene A cytotoxin (CagA), responsible for releasing the immune response, which in this case is insufficient to eradicate the infection. Furthermore, due to HP infection suppressor genes, p53 and CDKN2A are inactivated, whereas the proinflammatory cytokines (IL-1 $\beta$ and TNF- $\alpha$ ) are overexpressed, which may result in progression to chronic gastritis, multifocal atrophy, dysplasia, metaplasia and development of adenocarcinoma [35].

Gastric cancer is twice as common in males as in females. According to worldwide statistics the gastric cancer morbidity rate in 2002 was 934000 people [8]. It is the main cause of death in China and Japan. Every year an estimated 300000 adults die as a result of this cancer. The lowest incidence has been noted in Turkey, Kuwait and Egypt [34].

In Poland in 2006, the gastric cancer morbidity rate accounted for $5.4 \%$ of all cases of cancers among men and $3 \%$ among women. The standardized mortality rates were respectively: 13.2 and 4.8 [9].

Cofactors for HP-related gastric cancerogenesis are: smoking, low fruit and vegetable consumption, canned and smoked food.
Chronic HP-related gastritis may also progress to MALT lymphoma originating from B cells. It has been found that MALT chromosomal translocations are linked to overexpression of nuclear factor $\kappa \mathrm{B}$.

Diagnosis of HP is usually made by: urease test, histological examination of the biopsied tissue, microbiological culture test, serological examination and molecular diagnostics detecting HP DNA. In 2005 Australian scientists and pathologists received the Nobel Prize for their discovery of HP.

Vaccinating children from the high-risk population against $\mathrm{HP}$ is the most effective prevention, however the vaccine is still in the final stage of development.

\section{Chlamydia trachomatis}

Until recently the Chlamydiae were classified as first protozoa, and then viruses. Since 1966 they have been assigned to the bacterial family. Their size ranges from 0.2 to $1.3 \mu \mathrm{m}$ and they present a unique life cycle: a metabolically inactive elementary body, which is an infectious form and the metabolically active reticulate body capable of replication. The human strains of Chlamydia trachomatis can be divided into 18 serotypes identified according to their major outer membrane protein, MOMP. The urogenital infections are induced by the D-K serotypes [37].

Chlamydia's life cycle averages between 40 and 70 hours and the incubation period between 5 to 21 days. Chlamydia trachomatis is one of the most common pathogen transmitted by sexual contact, particularly among young sexually active people; it may not cause any symptoms in 40 to $75 \%$ of cases [38].

Chlamydia trachomatis infection is even more common worldwide; it is estimated that in Western Europe between 2003 and 2005 the incidence rate was 250 cases/100 000 per year [39]. It has been proven that Chlamydia trachomatis is a cofactor for precancerous conditions and cervical cancer [4-6].

Antilla et al. [37] determined DNA of HPV 16, 18 and 33 and 10 serotypes of Chlamydia trachomatis and Chlamydia pneumonia in women with invasive cervical cancer (ELISA and immunofluorescent tests). On the basis of this research they stated that Chlamydia trachomatis G serotype was diagnosed significantly often in those patients (OR 6.6; 95\% $\mathrm{Cl}$ : 1.6-27.0). Other types of Chlamydia trachomatis associated with cervical cancer are: I serotype (OR 3.8; 95\% Cl: 1.311.0) and $D(O R 2.7 ; 95 \% \mathrm{Cl}: 1.3-5.6)$. The risk of infection with B serotype was described as borderline (OR 2.7; 95\% Cl: 1.3-5.6).

Exposure to more than one Chlamydia trachomatis serotype was linked in a statistically significant way with the risk of developing a cervical cancer $(p<0.001)$. How Chlamydia trachomatis reinforces persistent HPV infection is not clear, the connection between the two in cervical carcinogenesis is proven.

\section{Parasites}

According to the findings of the IARC from 2009, parasites with proven carcinogenic properties in humans include: Schistosoma haematobium, Opisthorchis viverrini and Clonorchis sinensis [5]. 
The shared mechanism that triggers parasite-related malignant carcinogenesis is the presence of a long-standing inflammation. In response to parasite infection, the cells of the immune system, most notably macrophages and eosinophils, release great amounts of oxygen radicals. They are commonly known for their destructive influence on cell structure and nucleic acids, which leads to mutation, genetic instability and neoplastic transformation. Chronic irritation and damage to the tissue due to presence of eggs, adult worms or their metabolic products result in attempts at quick repair through cell proliferation and tissue hyperplasia. Acceleration in cell division promotes replication of DNAdamaged cells, while prolonged inflammation aids the development of new and accumulation of "old" mutations. Also, the MIF protein (macrophage migration inhibitory factor) produced by macrophages reduces the transcription activity of p53 protein, one of the key proteins responsible for DNA repair processes and apoptosis in cells [40].

\section{Schistosoma haematobium}

Parasites of the Schistosoma genus are one of the most widespread worldwide. Approximately 200 million people are affected by schistosomiasis. The parasites can be found mainly in tropical and subtropical regions of e.g. China, the Near East, Africa, and South America.

Mainly three Schistosoma species infect humans, namely S. haematobium, S. mansoni, S. japonicum, yet it is only S. haematobium that has a proven carcinogenic effect leading to the development of urinary bladder cancer. Unlike Europe and North America, where more than 90\% of urinary bladder cancers are urothelial cancers, in the endemic regions squamous cell carcinoma, the histological hallmark of infection with this pathogen, dominates significantly.

Infection takes place when a person comes into contact with water contaminated with larval cercariae. The cercariae have the ability to actively penetrate human skin (the definitive host), enter the blood stream and migrate to the liver where they attain sexual maturity. After copulation adult female flukes travel to urinary bladder vessels where they hatch eggs. With the use of a spicule, the eggs traverse the walls and travel to the lumen of the urinary bladder and eventually are eliminated from the host body through micturtion. The further development of the parasite may only take place in fresh water, where the eggs hatch into the larval form - miracidia. The intermediate host of S. haematobium is a snail, in which the miracidia pass their successive developmental stages, to finally leave the snail and enter the water in the form of cercariae and search for their definitive host.

In massive infections the $S$. haematobium eggs form large conglomerates in the bladder wall causing ulcerations when passing to the lumen of the bladder, which manifests as haematuria. Damage to bladder mucosa leads to inflammation, in chronic conditions progressing to pseudo-polypoid hyperplasia, fibrosis, calcification and bacterial superinfection.

As already mentioned, chronic inflammation induces inflow of macrophages and eosinophils, which release oxy- gen radicals, and this in turn is conducive to DNA damage and mutations distorting the activity of suppressor genes and oncogenes responsible for regulation of the cell life cycle. Studies have found that in comparison to other histological types, squamous cell carcinoma of the bladder induced by chronic schistosomiasis presents much more frequent mutations within p53 protein [40]. In cancer cells, the expression of 27 suppression gene is reduced, whereas the production of the anti-apoptotic $\mathrm{Bcl}-2$ protein is increased [41].

Urineanalysis of patients with S. haematobium reveals a high concentration of nitrosamines which are well known carcinogens. They are formed as a result of secondary bacterial infections of the bladder by reducing the nitrates present in urine to nitrites, which together with other amino compounds are metabolized to nitrosamines with the use of bacterial enzymes.

\section{Opisthorchis viverrini and Clonorchis sinensis}

Although primary sclerosing cholangitis, ulcerative colitis (UC) and pancreaticobiliary maljunction (PBM) are among the risk factors for cholangiocarcinoma, the leading cause of this cancer in East Asia is an infection induced by flatworms from the family Opisthorchiidae, 0 . viverrini and C. sinensis. It is estimated that around $9 \mathrm{~m}$ people are infected with 0 . viverrini in Thailand while $7 \mathrm{~m}$ people in Korea, Vietnam and China live with C. sinensis [42].

Infection is acquired mainly when people ingest raw or undercooked fish. The majority of infections are asymptomatic or manifest with mild diarrhoea, dyspepsia or pain in the abdomen. In chronic infection symptoms may proceed to inflammation of the bile ducts and gall bladder as well as to the development of cholangiocarcinoma.

The life cycle of both parasites is similar and involves many intermediate hosts. First, eggs excreted with faeces into a fresh water reservoir are ingested by snails. Miracidia hatch inside the snails and then undergo their next developmental stages (sporocyst, redia) to finally reach the form of cercariae. They are then shed into the water where they locate their next intermediate host (fish). By actively penetrating their host's body, cercariae encyst in the musculature and fins and develop into their next form, metacercariae. By ingesting raw or undercooked fish, humans become infected with this encysted form of flatworms. The young adult worms escape from the metacercarial cyst in the upper small intestine, usually in the duodendum, and then migrate through the ampulla of Vater into the biliary tracts, where they develop to sexual maturity over four to six weeks. The hermaphroditic adults, which are 10 to $15 \mathrm{~mm}$ in size, can live in the bile ducts for many years producing ca. 200 eggs per day. The eggs together with bile are transported to the intestine. Next they are released with faeces and particularly in countries with low hygiene standards contaminate fresh water reservoirs.

The process initiated with infection and leading to bile duct cancer is complex. The longstanding presence of the parasite in the bile duct causes systematic mechanical damage to the mucosa, as well as chronic inflammation due to the toxic influence of $O$. viverrini and $C$. sinensis metabolic 
products excreted by $O$. viverrini and $C$. sinensis. Further research has shown however that the chronic inflammation is not the only factor responsible for the carcinogenesis. Indeed, the parasites can also produce proteins that induce increased proliferation in cells. Laha et al. [43] have identified a gene in O. viverrini, which shares the same sequence with a progranulin gene. Progranulin is a pluripotential growth factor which partakes in the regulation of cell division. It also participates in the wound healing and inflammatory processes. Significantly strong progranulin expression has been detected in haematopoetic and epithelial cells. However increased expression of this gene has also been noted in many cancer types affecting the cell life cycle and stimulating cell proliferation. Another compound produced by $O$. viverrini is a protein similar to serine protease of the kallikrein family, which takes part in cancer progression. C. sinensis in turn produces proteins that induce cell proliferation by increasing the concentration of cyclin $\mathrm{E}$ and transcription factor E2F1 [44].

To sum up, the relation between chronic inflammation and cancer development is complex and not clear at all stages. One may assume that apart from anti-pathogen vaccines, efficient targeted therapy of chronic inflammatory conditions associated with high-risk of cancers and precancerous states will be made available.

\section{References}

1. Higginson J, Muir CS. Determination of the importance of environ mental factors in human cancer; the role of epidemiology. Bull Cancer 1977; 64: 365-84.

2. Goswami B, Rajappa M, Sharma M, Sharma A. Inflammation: its role and interplay in the development of cancer, with special focus on gynecological malignancies. Int J Gynecol Cancer 2008; 18: 591-9.

3. Philip M, Rowley DA, Schreiber H. Inflammations as a tumor promoter in cancer induction. Semin Cancer Biol 2004; 14: 433-9.

4. Bouvard V, Baan R, Straif K, et al. A review of human carcinogenes. Part B: biological agents. Lancet Oncol 2009; 10: 321-322.

5. Centers for Disease Control and Prevention, MMWR 2007; 56: RR 2: 1-23.

6. Muñoz N, Castellsagve X, de Gonzales AB, Gissmann L. Chapter 1 HPV in the etiology of human cancer Vaccine 2006; 24, Suppl. 3: S3: 1-10.

7. Parkin M. The global health burden of infection-associated cancer in the year 2002. Int I Cancer 2006; 118: 3030-44.

8. Parkin M, Bray F, Pisani P. Global Cancer Statistics, 2002. CA Cancer J Clin 2005; 55: 74-108.

9. Wojciechowska U, Didkowska J, Zatoński W. Nowotwory złośliwe w Polsce w roku 2006. Centrum Onkologii Instytutu im. Marii Skłodowskiej-Curie, Warszawa 2008.

10. Wallboomers JM, Jacobs MV, Manos MM, et al. Human papillomavirus is a necessary cause of invasive cervical cancer worldwide. J Pathol 1999; 189: 12-9.

11. Harper DM. Expert reviews. Currently approved prophylactic HPV vaccines 2009; 8: 1663-79

12. British Association of Sexual Health and HIV, Clinical Effectiveness Group: United Kingdom national guideline on the management of the Vidal hepatitides A, B \& C 2005; <http://www.bashh.org/eweb/ docs/chronichep_B.pdf.

13. Koshy R, Maupas P, Müller R, Hofschneider P. Detection of hepatitis $B$ virus-specific DNA in genomes of human hepatocellular carcinoma and liver cirrhosis tissues. J Gen Virol 1981; 57: 95-102.

14. Tokino T, Fukushige S, Nakamura T, et al. Chromosomal transloca tion and inverted duplication associated with integrated hepatitis B virus in hepatocellular carcinomas. J Virol 1987; 61: 3848-54.
15. Takada S, Tsuchida N, Kobayashi M, Koike K. Disruption of the function of tumor-supresor gene $\mathrm{p} 53$ by the hepatitis B virus $X$ protein and hepatocarcinogenesis. J Cancer Res Clin Oncol 1995; 12: 593-601.

16. Strader DB, Wright T, Thomas DL, et al. Diagnosis, management and treatment of hepatitis C, AASLD practice guideline. Hepatology 2004; 39: 1147-71.

17. Adamek A. Rola zakażeń wirusami HBV i BCV w rozwoju pierwotnego raka wątroby. Współcz Onkol 2000; 2: 61-4.

18. Dobrzańska J, Sawczuk-Chabin J, Warzocha K. The role of viruses in etiopathogenesis of non-Hodgkin lymphomas. Onkol Prakt Klin 2006; 2: $\mathrm{nr} 2$.

19. Benson C, Kaplan J, Masur H, et al. Treating of opportunistic infections among HIV-infected adults and adolescens. MMWR Recomm Rep 2004; 53: 1-112.

20. Yeni PG, Hammer SM, Hirsch MS, et al. Treatment for adult HIV infection: 2004 recommendations of the International AIDS Society-US Panel. JAMA 2004; 292: 251-65.

21. Simon K, Pazgan-Simon M. Infectious factor and development of neoplastic diseases E\&C Hepatology 2006; 2: 24-8.

22. Epstein MA, Achong BG, Barr YM, et al. Virus particles in cultured lymphoblasts from Burkitt's lymphoma. Lancet 1964; 1: 702-3.

23. Clarke CA, Glaser SR, Dorfman RF, et al. Epstein-Barr virus-associated Hodgkin's disease: epidemiologic characteristics in international data. Int J Cancer 1997; 70: 375-82.

24. Klein G, Klein E. Epstein-Barr virus and human lymphomas. The Lymphomas W.B. Saunders Company, Philadelphia 1998; 63-73.

25. Samanta M, Takada K. Modulation of innate immunity system by Epstein-Barr virus-encoded non-coding RNA and oncogenesis. Cancer Sci 2010; 101: 29-35.

26. Juszczyński P, Warzocha K. Czynnik martwicy nowotworów: przekazywanie sygnału wewnątrzkomórkowego, molekularne mechanizmy ekspresji i udział w patogenezie chorób zapalnych i chłoniaków. Acta Haematol Pol 2002; 33: 191-203.

27. Pioesz BJ, Ruscetti FZ, Reitz MS, et al. Isolation of a new type C retrovirus (HTLV) in primary uncultured cells of a patient with sezary T-cell leukaemia. Nature 1981; 294: 268-71.

28. Proietti FA, Carneiro-Proietti AB, Catalan-Soares BC, et al. Global epidemiology of HTLV-I infection and associated diseases. Oncogene 2005; 24: 6058-68.

29. Feuer G, Chen IS. Mechanism of human T-cell leukemia virusinduced leukemogenesis. Biochim Biophys Acta 1992; 1114: 223-8.

30. Richardson JH, Hollsberg P, Windhagen A, et al. Variable immortalizing potential and frequent virus latency in blood-derived T-cell clones infected with human T-cell leukemia virus type I. Blood 1997; 89: 3303-14

31. Franchini G. Molecular mechanism of human T-cell leukemia/lymphotropic virus type 1 infection. Blood 1995; 86: 3619-24.

32. Armstrong AP, Franklin AA, Uittenbogaard MN, et al. Pleiotropic effect of human T-cell leukemia virus Tax protein on the DNA binding activity of eucariotic transcription factors. Proc Natl Acad Sci U S A 1993; 90: 7303-7.

33. Ballaun C, Farrington GR, Dobrovnik M, et al. Functional analysis of human T-cell leukemia virus type I Rex-response element: direct RNA binding of Rex protein correlates with in vivo binding activity. J Virol 1991; 65: 4408-13.

34. Classen M, Prinz Ch, You W-Ch. Helicobacter pylori: a bacterium than can lead to cancer UICC Report 2010. Protection against stomach cancer - causing infections. 2010; 35 -39.

35. de Martel C, Franceschi S, Infections. Cancer Report 2010 ed. A. Murat Tencer. Asian Pacific Organization for Cancer Prevention (APOCP) p. 38

36. Agarwal K., Agarwal S., Helicobacter pylori vaccine: from past to future. Mayo Clin Proc 2000; 6: 228-37.

37. Anttila T, Saikku P, Koskela P, et al. Serotypes of Chlamydia trachomatis and risk for development of cervical squamous cell carcinoma. JAMA 2001; 285: 47-51.

38. Zdrodowska-Stefanow B, Ostaszewska I. Chlamydia trachomatis zakażenia u ludzi. Volumed, Wrocław 2000.

39. WHO Regional Office for Europe. Technical briefing document 01B/06:Trends in sexually transmitted infections and HIV in the European Region, 1980-2005. Copenhagen, 12 September 2006: http://www.euro.who.int. 
40. Chaudhary KS, Lu QL, Abel PD, et al. Expression of bcl-2 and p53 oncoproteins in schistosomiasis-associated transitional and squamous cell carcinoma of urinary bladder. Br J Urol 1997; 79: 78-84

41. Botelho M, Ferreira AC, Oliveira MJ, et al. Schistosoma haematobium total antigen induces increased proliferation, migration and invasion, and decreases apoptosis of normal epithelial cells. Int J Parasitol 2009; 39: 1083-91.

42. IARC. Summaries and Evaluations: Infection with liver flukes; 1994; 61: 121.

43. Laha T, Pinlaor P, Mulvenna J, et al. Gene discovery for the carcinogenic human liver fluke, Opishorchis viverrini. BMC Genomics 2007; 8: 189.

44. Kim YJ, Choi MH, Hong ST, et al. Proliferative effects of excretory secretory products from Clonorchis sinensis on the human epithelial cell line HEK293 via regulation of the transcription factor E2F1. Parasitol Res 2008; 102: 411-7.

\section{Address for correspondence}

\section{Anna Markowska, MD}

Department of Perinatology and Gynecology

Poznan University of Medical Sciences

33 Polna St.

60-535 Poznan (Poland)

e-mail: annamarkowska@vp.pl 